\title{
Using an L2 blog to enhance learners' participation and sense of community
}

\author{
Tiziana Miceli, Sara Visocnik Murray and Claire Kennedy \\ Griffith University
}

\begin{abstract}
This paper describes the experience of integrating a class blog into an advanced Italian course, in order to provide an out-of-class forum for language practice and for sharing course-related ideas and information. It also reports on an evaluation of the blog's effectiveness, drawing on an analysis of the students' blog contributions and their responses to questionnaires. We argue that blogs can play a significant role in promoting learners' interaction and nurturing a sense of class community. For this to happen, however, requires careful attention to two key aspects: the way in which the use of the blog is integrated into the course content and structure; and the teachers' role in moderating and facilitating blog interaction.
\end{abstract}

\section{Introduction}

Online communication tools such as discussion boards, chat rooms, blogs and, more recently, wikis offer valuable ways of blending out-of-class interaction with in-class learning, especially in the tertiary education sector. One tool that continues to generate significant interest, due to its support of interactivity and content sharing, is the blog (Ducate \& Lomicka, 2008). In the context of second and foreign language learning and teaching, blogs can notably increase students' access to authentic material and opportunities for genuine communication in the target language.

This paper reports on the experience of introducing a class blog in an advanced course in Italian language and culture called "Italy Through Food", at an Australian university. The blog La mensa (the Refectory) was designed to provide students with additional out-of-class reading and writing practice and to encourage further sharing of ideas and information on the topics discussed in class. After setting out the rationale for La mensa and describing its implementation, we discuss our evaluation of its impact in relation to our objectives. Specifically, we investigate the extent of the students' participation and, through analysis of their communication patterns in the blog and their reported perceptions of the experience, the function of the blog in nurturing a sense of class community.

\section{Blogs in language learning}

The application of blogs to second and foreign language learning has seen increasing interest in the last few years. Several studies have explored the suitability of blogs for language learners, identified potential benefits and/or described implementations of blogging in various learning contexts (Arena, 2008; Ducate \& Lomicka, 2005;

Godwin-Jones, 2003, 2006; Murray \& Hourigan, 2008; Stanley, 2005). Meanwhile, there has also been considerable attention to evaluating the effectiveness of blogs and reporting on students' experiences and outcomes (Ducate \& Lomicka, 2008; Lee, 2006; Murray \& Hourigan, 2008; Petersen, Divitini, \& Chabert, 2008, 2009; Pinkman, 2005; Ward, 2004). 
We see three areas in which the potential of blogs for enriching the language learning experience appears particularly significant. First, there is the expectation that blogs can provide a valuable dimension of authenticity to learners' reading and writing experiences in the target language (Lee, 2006; Pinkman, 2005). Egbert (2006) highlighted the value of ensuring CALL applications in general support activities around authentic language and content. Certainly the potential of blog technology to support the exploitation of authentic material is clear, as it enables the uploading and linking of files and allows easy access to written and audiovisual Web content via hypertext links. But if, with Van Lier (1996, p.128), we consider authenticity as not only about material from the "real' world but "a personal process of engagement" for learners, linked to "self determination and commitment to understanding", then we can see that the key potential of blogging lies in providing for authenticity of interaction (Castro, 2007). When blogging, learners can use the target language for authentic communication purposes (Arena, 2008; Campbell, 2004; Godwin-Jones, 2003), with implications for motivation (Richardson, 2006; Ward, 2004). As Ward (2004) pointed out, the perception by learner writers that traditional scholastic tasks are just about delivering a product to the teacher, and of little significance to anyone else, may be what makes such tasks sometimes appear difficult and uninspiring. In a blog, however, dialogue with a real audience, through participation as both writer and reader, should provide a stimulus for writing while also raising awareness of the recursive process of writing, as the participants are encouraged to revise and edit their work in response to their peers' comments (see also Stevens, 2004).

Second, there is the potential for blogs to activate learners who are quiet in class due to shyness or anxiety. Roed argued that "when communicating online, people show fewer inhibitions, display less social anxiety, and reduce their public self-awareness" compared with face-to-face classroom situations (2003, p.155), with obvious benefits for shy students. Indeed, Ward (2004, p.5) found that some of the most open and forthcoming students in blogs were the shyest and least talkative students in class, while Lee (2006) reported that learners felt less concerned in the blog that others would criticise their errors. Ducate and Lomicka (2008, p.18) found their blogging students to be "comfortable expressing themselves more openly than in class" which the authors attributed to being able to take time to think before writing and to the "personal nature" of blogs. However, Petersen, Divitini, and Chabert (2008, 2009) reported that their students were shy about publishing material on the blog, especially in the target language. The authors wondered if this were due to a lack of confidence and/or lack of trust among the group of learners concerned, which they linked to a lack of sense of community.

This brings us to the third expected benefit: the potential of the blog to provide a forum for authentic communication among all learners in an L2 class implies the potential to nurture a feeling of belonging to a class community (Petersen, Divitini, \& Chabert, 2008, 2009; Stanley, 2005). With respect to the classroom environment, Dörnyei (1997) argued that group cohesion is one of the important components of motivation and directly linked to performance in the L2, that a "warm, cohesive group climate significantly enhances peer interaction" as "communication is unfolded and enlivened in positive relationships" (pp.485-487). Dörnyei (2007, 2001, see also Dörnyei \& Murphey, 2003) also maintained that, while class cohesiveness can be promoted gradually by the experience of a class-group, it can also be actively encouraged by language instructors. One important strategy he identified is to create 
an environment in which the focus is on peer collaboration rather than competition, so that students learn from each other, encouraging greater acceptance and therefore risktaking in communication in the target language.

As for the online environment, a couple of studies have investigated whether blog discussions can help foster a sense of community among language learners. These studies have referred to different conceptions of sense of community. For Ducate and Lomicka (2008), one of the purposes of encouraging their students to blog was to build a community in the sense that the students would interact and collaborate, by reacting to each other's entries through their comments. Instead, the authors observed: "[W]e found the blogs functioned more as a private space for students to describe, explore, and express their own ideas and feelings in the [target language] without needing input from other students" (p.24). It is worth noting that, in this case, each student created an individual blog, to which the others were only able to comment, rather than all students contributing to a collective class blog. Although Ducate and Lomicka did not obtain the results they had hoped for in terms of creating a community, they noted that the students did report that they appreciated getting to know each other in a "deeper" way than they did in class discussions, because of the personal nature of many of their blog contributions (pp.18-19).

Petersen, Divitini, and Chabert $(2008,2009)$ reported on the experience of a mobile blog designed specifically to create a sense of community among students and then maintain it while the class was divided, with some students away in the targetlanguage country. The authors were concerned with sense of community in relation to the learners' identity as members of a community of practice, manifested by active participation in the blog for the purposes of social interaction and collaboration on tasks. On analysing the level of usage and the content of the blog, and through student interviews and diaries, they found that no sense of community was manifested by their students - whether abroad or remaining on campus - and that they did not perceive themselves to have an identity as part of a specific community of learners. Indeed, most of the students used the blog very little. The authors found that, although the blog provided an arena for sharing and collaboration, this had not led to the development of intellectual, emotional and pedagogical connectedness. They proposed to address this in future by improving some technical aspects of the implementation and integrating the blog use more directly into the course work.

A useful approach to understanding what sense of community means in an online environment, and how it can be manifested and measured, is offered by Rovai. Rovai (2002) developed a self-report questionnaire for measuring sense of community among a group of students, whether in a traditional or virtual classroom: the Classroom Community Scale. This generates subscales for connectedness and learning, and contains items related to "feelings of connectedness" and "feelings regarding the use of interaction within the community to construct understanding and the extent to which learning goals are being satisfied" (2002, p.202). A second way of exploring sense of community in an online class used by Rovai (2001) is through analysis of the communication patterns in the students' contributions to an online discussion, looking for 'connected voice' patterns - expected to nurture classcommunity building - and 'independent voice' patterns - expected not to do so. In this approach, connected voice patterns are those that reflect a relational, interdependent learning path, taken by those who prefer learning in an environment 
where cooperation prevails over competition and relationships are supported, whereas independent voice patterns tend to be impersonal and assertive, reflecting an independent learning path.

Rovai's (2001) study of 20 adult learners in a 5-week fully online course found that the students with higher sense-of-community scores ${ }^{1}$ were more likely to use connected voice and those with lower sense-of-community scores were more likely to use independent voice. Women displayed much higher rates of connected voice and men higher rates of independent voice. In general, those students who posted more messages to the discussion forum tended to have higher sense-of-community scores at the end of the course.

Rovai hypothesised that the significant increase in sense of community observed in the cohort over the five weeks was largely due to the high degree of interaction and involvement of the learners - the high number of messages each week per learner serving to lessen psychological distance. This in turn he attributed partly to the emphasis placed on discussion by the instructor concerned, through its inclusion in the course assessment and the provision of a guidelines rubric. That is, Rovai highlighted the importance of the instructor's work, in designing the forum and facilitating discussion, towards building the sense of community.

Our perception of the potential benefits of blogging discussed above - in providing for authentic communication, involving shy students, and building a sense of class community - led us to introduce blogging into our Italian programme, where we envisaged blogs as providing an appealing outside-class component of our on-campus courses. Helping students make effective use of outside-class time is a key concern of ours, as we seek to support students' development as independent, strategic and reflective learners (Miceli \& Visocnik Murray, 2005).

\section{The design of La mensa blog}

$\mathrm{We}^{2}$ introduced blogging in the programme for the first time as part of the design of a new third-year course "Italy Through Food". This is an advanced course which seeks to develop linguistic and analytical skills through exploration of the ways in which food shapes contemporary Italian cultural practices. As a major part of the assessment, each student investigates a chosen topic in relation to the cultural, social and economic issues surrounding food production, consumption and representation in today's Italy, and shares the findings through an oral presentation in class.

Within this course, we created La mensa (the Refectory) as an online communal space for sharing course-related ideas and information. In practical terms, we saw it as providing an easily accessible venue for extending interaction beyond class time - the ration of three contact hours per week being always insufficient for students at this level, given their intense engagement with the subject matter and a level of proficiency that allows them to translate that engagement into discussion in Italian. In pedagogical terms, the literature discussed above suggested three key potential benefits. First, we expected the blog to encourage the students to both write and engage in extensive reading for authentic purposes. Second, we hoped it would render course discussions more inclusive, by encouraging the participation of shy students. Third, we saw the blog as creating an online class-group, which could maintain 
contact anytime and anywhere, thus fostering a sense of community beyond the classroom walls. This is particularly significant in our context, as the students come from various faculties and campuses and some invariably face attendance constraints. This not only creates difficulties for them in keeping up with course work, but can also leave them feeling isolated from the class-group.

We chose to use a blog rather than a discussion forum because we saw the blog as a tool that would be easy to use while providing an excellent range of functions, allowing students to post comments to build discussion threads, publish and edit their texts, and make hypertext connections to related content on the Web. As Tan et al. (2005) pointed out, a key to the educational benefit of blogs is their rich content. We considered the blog facility particularly conducive to creating a visually appealing and stimulating environment within which to extend students' interaction with course materials and with each other. ${ }^{3}$

One key design decision was that La mensa should be a class blog rather than a learner blog or tutor blog, with reference to Campbell's (2003) definition of three types of blogs used in language courses. We opted for a class blog so as to provide a single shared space, rather than a set of individual students' blogs, and one in which students' participation would not be restricted to commenting on teachers' entries.

The second key design decision was to establish a strong connection between $L a$ mensa (in both its structure and content) and the course content and assessment. The platform we used, developed by our university ${ }^{4}$, has two features distinctive to blogs that we found essential: a blog roll for links to other Web pages, which allowed us to provide easy access to a selection of useful language and food-culture sites; and an archiving function that automatically sorted the content by date and category. We created categories in four areas. In the first category, Commensali (Table companions) all members introduced themselves at the start, beginning with the teachers. The second area contained a series of categories for general discussion threads, where we sought to continue discussion of each week's in-class topics (see Figure 1). For example, an entry posted by the teacher in the category Cibo e cinema (Food and film) invited students to comment on scenes viewed in class from Le fate ignoranti (His Secret Life, by Ferzan Özpetek, 2002), analysing the role played by commensality in this film in light of academic readings. The category Portate (Dishes, as in a menu) was for students' entries foreshadowing their oral presentations, which the others could read and comment on both before and after the delivery in class. Finally, the Momento digestivo (Ruminations) category gathered students' reflections on their own relationship with food while 'digesting' all the input from the course. Figure 2 shows an excerpt from a student's Momento digestivo entry on his discovery of tartufi (truffles).

We followed Campbell's (2003) recommendation to include blog participation in the assessment requirements for the course. The students were expected to:

- add a comment in the Commensali category introducing themselves;

- post an entry in the Portate category prior to their class presentation;

- post an entry in the Momento digestivo category presenting a personal reflection on the functions and meanings of food preparation and consumption in their life; 
- post entries of their choice, related to the course themes, in order to initiate discussion threads in any category;

- add comments to threads initiated by teachers' and other students' entries in any category.

When composing entries to initiate threads (primarily in the Portate and Momento digestivo categories), the students were asked to pay attention to accuracy of language and appropriate structure and to seek a teacher's feedback prior to posting them. However, in making comments - that is, adding to any existing threads - they were encouraged to focus on getting their meaning across, without letting concern for language form interfere with the flow of communication.

We saw our role in La mensa as that of both facilitator and participant. Much of the time we acted as facilitators, monitoring blog activity and feeding the conversation regularly by posting entries to initiate new discussion threads on topics treated in class, and by adding challenging comments to threads already under way. In this way we sought to encourage further reflection on concepts encountered, guide students to relevant resources, and generally stimulate their interaction. Often, however, our comments were the contributions of ordinary participants, made without any leadership intent or pedagogic motive. This was deliberate when we introduced ourselves to launch the Commensali thread, but subsequently often happened spontaneously, when we joined in an exchange of personal experiences simply because we felt drawn in.

\section{Evaluation of the implementation of La mensa}

\section{Aims and method}

We conducted an evaluation of the students' experience of La mensa in the first year of its existence, in order to investigate how well it had served the aims in creating it, outlined above. In the rest of this paper we report on some aspects of that evaluation process. Specifically we address the following questions:

1. To what extent did the students participate in the blog, by contributing to it and reading it?

2. Was the blog conducive to nurturing a sense of community among the students?

The class was made up of 17 students -15 women and two men. The majority (12) were in the 20-24 age group, with two aged between 25 and 34 and three over 45 . In light of our interest in the presence of a sense of community, it is important to note that 14 of the students had just completed one or both of our first-semester third-year courses and therefore moved forward together into "Italy Through Food", while the other three were new to the cohort. (See Table 1 for a summary of these characteristics). For all the students, however, the amount of contact with fellow students outside class varied greatly, according to the degree programmes they were enrolled in, their full-time or part-time status, their family and work commitments, and whether ours was their home campus or they were cross-registered from another university. Contact was particularly reduced for three of the students due to a sixweek full-time school-teaching practicum. 
One source of data was the blog itself: we analysed the content quantitatively and qualitatively as set out below. We also collected data through two non-anonymous questionnaires, both made up largely of open questions. The start-of-semester questionnaire, completed by 16 students, was concerned with their expectations and any prior blogging experience, while the end-of-semester questionnaire, completed by all 17 students, was aimed at capturing their perceptions of using La mensa.

To answer the first research question, on the extent of students' participation in the blog, we first tallied the numbers and lengths of their contributions. We counted only the words written in Italian by the students themselves, including any material translated by them from English: the few chunks excluded were recipes copied from Italian Internet sites or books. Any contribution that amounted to a post-script to a previous contribution (such as "Sorry, I forgot the link - here it is") was considered part of that previous contribution rather than a separate one. To measure the extent of the students' blog reading, we compiled their responses in the end-of-semester questionnaire to the closed question "How often did you read the blog?" and the open question "How did you read the blog?". In order to gain some understanding of reasons for variation in the extent of participation among the students we examined their answers to other questions about their experience of the blog.

In addressing the second research question, on the development of a sense of community, we measured the proportion of the students' blog contributions that manifested connected voice or independent voice, in light of Rovai's (2001) argument that a higher sense of class community is associated with greater use of connected voice and a lower sense of community with use of independent voice. Rovai's (2001) study of connected voice and sense of community in a fully online class also provided the benchmark for comparison; we found no other studies that measured the rate of use of connected voice and independent voice in an online students' forum.

In our analysis of the blog content, the essential criterion we used for labelling a word pattern as exhibiting connected voice was that it was consistent with Rovai's (2007, p.85) statement that a connected voice "emphasizes socialization, caring, cooperation, consensus, and the indirect resolution of conflict". We defined eight types of connected voice patterns for our purposes, the first three borrowed from Rovai's (2001, p.41) definition "Connected voice patterns consisted of text that referenced self or family; made reference to another learner's family; described personal experiences; offered praise and encouragement; or used supporting statements of agreement such as 'you're right' or 'that's true' ", and the other five derived following observation of our data. ${ }^{5}$ Our eight types were:

a) talking about oneself or one's family, relating a personal experience or making a confession (but not including basic statements of preferences and actions which are not elaborated upon, such as: "I've read this site and it seems interesting" or "I went to ... delicatessen and checked out the range of ...")

b) offering praise or encouragement to another student

c) making a supporting statement of agreement to another student

d) apologising, such as for a delay in responding to a comment (but not including what can be considered routine apologising in PS-like contributions supplying a link accidentally left out of the previous message)

e) explicitly presenting one's own points as possibly mistaken and open to correction (for example, adding "But I realise this may be wrong so please 
correct me if you think so" after making a point), or emphasising that they are a matter of opinion (beyond expressions like "I think" or "in my opinion"), or apologising for the quality of one's translation

f) making it clear when a comment is intended as a joke, in order to prevent misunderstandings

g) asking other students for help or confirmation in relation to the interpretation of material in Italian

h) expressing complicity among the group, as separate from the teachers (for example, reacting to a teacher's comment with "... but could this be a trap she's set for us?" in a joking tone)

Our definition of independent voice was based on Rovai's (2001, p.41): "Independent voice patterns consisted of text that was arrogant, argumentative, confrontational, defended or asserted self, disagreed, or contained rude or hostile remarks". However, we found the inclusion of disagreement in the list problematic, as we found various instances in La mensa of our students disagreeing with each other but in ways which did not constitute being arrogant, argumentative, confrontational, rude or hostile, or defending or asserting oneself. In the analysis we therefore examined each case of a student expressing disagreement carefully, to decide whether the intention was such as to warrant considering it a case of independent voice.

The identification of connected voice and independent voice patterns in the students' messages was carried out initially by one author and then separately by a second rater who was not one of the authors. The few discrepancies in the outcomes were examined jointly and the contributions concerned classified to the satisfaction of both raters.

Only the general discussion threads were included in this analysis, because we were interested in the incidence of connected voice in the threads where the students were engaged primarily in task-based interaction. That is, we excluded the threads that particularly lent themselves to personal references (Commensali and Momento digestivo threads) or expressions of support for fellow students (Portate threads), and that we therefore saw as encouraging connected voice by their nature.

Also in relation to the second research question we considered the students' responses to the question "Do you think that using the blog influenced - positively or negatively - your feeling of belonging to the class-group and the way you see the class-group?", in the end-of-semester questionnaire. We then examined the students' blog contributions for indications of attitudes towards the class-group, especially on the part of those who said they did not perceive the use of the blog as having changed their view of it.

\section{Results}

\section{The students' participation}

Our first research question was: To what extent did the students participate in the blog, by contributing to it and reading it? 
As shown in Table 2, all students contributed to the blog but there was considerable variation in the frequency and length of their contributions. The mean number of contributions per student was 13.2, the maximum 26 and the minimum 4, while the mean number of words per student was 1884, the maximum 3962 and the minimum 836. Given that the semester was of 13 weeks duration, the mean of 13 contributions amounted to 1 per week, and the maximum to 2 per week. The set of 22 general discussion threads attracted a mean of 6.8 contributions and 776 words per student, with a maximum of 17 contributions and 2490 words, and a minimum of 1 contribution and 118 words.

We were pleased by the extent of the students' contributions and considered their writing practice in this course therefore compared very favourably with that in our other third-year courses. This was firstly a matter of quantity: given that the students also wrote an essay in this course, they produced many more words overall in their during-semester tasks (that is, leaving aside the written exam at the end) than in the other courses, where the written homework tasks require approximately 1000 words in all. Indeed, 14 of the 17 students wrote more than 1000 words in the blog alone. Secondly, in this course there was a mix of controlled writing, in the essay and the Portate and Momento digestivo blog entries (marked on accuracy, complexity and fluency of language and quality of content), and freer writing in the blog comments (marked on extent of participation), while the writing tasks in our other courses tend to be wholly of the controlled type. The mix is especially important given that 9 out of 16 students reported in the start-of-semester questionnaire that they never wrote in Italian for purposes other than to meet course requirements, and a further three said they did so only every few months.

The blog seemed to be particularly successful in providing a forum for those who found it difficult to speak much during in-class discussion. In the end-of-semester questionnaire, two of the students who tended to speak least in class reported:

- "I found it easier to participate on the blog because I feel a lot more shy in class" (S13; 13 contributions, 1622 words)

and

- "... with the blog you can take your time, whereas with face to face you have to think on the spot. Often by the time I worked out what I wanted to say in class the discussion had moved on or someone stole my idea" (S2; 11 contributions, 962 words).

Others also appreciated the blog because there was time to prepare exactly what they wanted to say or to come up with extra points that had not been discussed in class (S1, S4, S7, S8, S12, S15 and S11). The second most prolific contributor added that she preferred the blog because "you don't interrupt anyone and nobody interrupts you" (S7; 25 contributions, 3857 words).

At the other extreme, the four who made the fewest contributions to the blog were students who consistently participated actively in in-class discussion (S16, S17, S3, $\mathrm{S} 15)$. In the end-of-semester questionnaire, three of these explained their relative lack of contribution to the blog in terms of a personal preference for face-to-face discussion. 
Only one student, S1, neither spoke much in class nor wrote extensively to the blog (8 contributions, 1036 words). Although she started out enthusiastic about the blog and contributing regularly (while speaking little in class), her engagement in the course overall lapsed after a few weeks, due largely to work commitments, and she lost confidence in her Italian. However, at the end of semester she still thought the blog was a good idea - "Being able to all have a say, even those who don't like talking in class" - and admitted she "didn't make proper use of it though ... it would definitely have helped [my Italian language and culture learning]".

None of the students appeared to experience technological barriers to contributing to the blog. Interestingly, the two oldest students, who did not consider themselves highly Internet-literate, were among the most prolific contributors (S8 and S9). Student S8, who reported "My problem mainly lies with the fact that I am very slow at both the composition and then putting it on the net. I only type very slowly", made 24 contributions comprising 3962 words, the highest total!

The majority of students also read the blog quite frequently, according to their responses to the end-of-semester questionnaire. As shown in Table 3, one student claimed to have read the blog three times a week on average, six students twice a week, another six at least weekly and one at least fortnightly, while the other three said they read at least weekly in the first half of the semester but only rarely by the end. Interestingly, the student (S1) discussed above, who neither spoke much in class nor wrote much in the blog, started the semester reading the blog assiduously, three times a week, and felt confident about it - "It allowed me to read something fairly easy, which actually gives me confidence because it's a sense of achievement not to have to look up heaps of words" - before losing motivation and giving up reading it as well as writing in it.

What the students meant by reading the blog varied. While ten students said they read all the contributions, the other seven described themselves as skimming all the contributions and then closely (re-)reading only those they found particularly interesting. Only one said she explored most of the links provided in teachers' and other students' contributions, while five said they sometimes did so and the rest made no mention of this in their responses. One student printed and translated all contributions while another printed some and translated some parts. Two said they took notes on contributions as they read them, to help them prepare their own, and two mentioned looking up words where necessary to understand others' contributions.

\section{Sense of community}

Our second research question was: Was the blog conducive to development of a sense of community among the students?

The analysis of the communication patterns in the blog produced results that were suggestive of a strong sense of community among the cohort: an incidence of connected voice that we considered unexpectedly high, and no cases of independent voice. Manifestations of connected voice were present in $63.8 \%$ of contributions to the general discussion threads, as shown in Table 4. Every student except one made some contributions that included connected voice patterns, while four students 
manifested connected voice in every contribution, and 11 did so in more than half their contributions.

In describing this incidence of connected voice as high, we are comparing it with the results of Rovai's (2001) study, in which there was an incidence of $19.89 \%$ for connected voice and $11.77 \%$ for independent voice. The rate of use of connected voice in our cohort still compares favourably even if we exclude from our calculations the instances of connected voice of types not explicitly mentioned by Rovai (types $d$, $e, f$ and $h$ ) or not applicable in his study (type $g$ ), resulting in an incidence of $50 \%$ among our cohort, or if we compare it only with that of the women in Rovai's group (29.1\%) who used connected voice much more than the men.

The most frequently occurring type of connected voice pattern was type $a$ ("talking about oneself or one's family, relating a personal experience or making a confession") with 51 occurrences of the total 91. This was followed by type $c$ ("making a supporting statement of agreement to another student"), identified 15 times, and type $e$ ("explicitly presenting one's own points as possibly mistaken and open to correction" etc.), occurring 13 times. (See Table 5).

As far as the lack of independent voice is concerned: we found the students did speak with authority at times, but not in a confrontational tone. And while there were several instances of expressing disagreement, this was achieved each time in a careful way, which we felt was clearly intended not to threaten cooperation. This is illustrated by the following extract, from a thread continuing the analysis begun in class of some TV advertisements for food items: ${ }^{6}$

S1: I agree in part with S7's and S17's comments. For me, the advertisements were very engaging. That is, ... Regarding S7's comments, I can understand the point of view that they strongly forced a certain type of Italian culture on the spectator. But given that the director wanted to make Barilla synonymous with Italy, family and happiness, it's understandable to make it like that. S17 also made interesting observations...

As to whether the students perceived the use of the blog as having made a difference to their sense of class community, Table 6 shows their responses to the relevant question in the questionnaire, along with our assessment of whether those responses implied a positive effect, negative effect or no effect. The table also shows each student's rankings in terms of the incidence of connected voice in her/his contributions and the number of words contributed.

Just over half the students (nine out of 17) indicated that their feeling of belonging to the class-group and the way they saw the class-group had changed positively - and some declared so quite emphatically - while none reported a negative effect. The comments conveying the perception of a positive effect included expressions very similar to those used in Rovai's (2002) Classroom Community Scale items; for example:

- "I feel much more connected ... to my classmates"

- "I think it made the group a more solid unit ... I really enjoyed the unity of the class"

- "I think it helped the sense of belonging" 
and even

- "It definitely helped build the class community".

Those perceiving a positive effect had a higher mean number of words and a slightly higher mean number of contributions than the 'no effect' group (2084 to 1651 words; 13.8 to 12.4 contributions), but Mann-Whitney $\mathrm{U}$ tests $^{7}$ found these differences not significant. Indeed, among the students reporting a positive effect were some of those who had contributed least, (S3, S16 and S17, ranked $13^{\text {th }}, 15^{\text {th }}$ and $17^{\text {th, }}$ respectively, on words contributed), while the group of eight who did not perceive any effect included the second most prolific student (S7) and four medium-level contributors (with 10-14 contributions each, or an average of approximately one per week).

Those perceiving a positive effect also had a higher mean incidence of connected voice than the 'no effect' group (75\% to $52.5 \%$ ), but again the difference was not statistically significant. The means again hide a broad distribution: the 'positive effect' group included the students ranked $10^{\text {th }} 12^{\text {th }}$ and $14^{\text {th }}$ for incidence of connected voice, while the 'no effect' group included one of the four students with $100 \%$ incidence of connected voice and five students with incidences of $50 \%$ and higher.

Even though eight students did not perceive the blog use as having changed their feelings about the class-group, all but one of them can be seen to have contributed to building the sense of community, given their use of connected voice. The exception is S15, whose (relatively few) contributions never included any connected voice patterns. However, it is interesting to note that her answer to the question about the effect of the blog on her feelings about the class-group was "I often didn't write in the blog and sometimes felt that I had missed something important", suggesting that she felt there was some kind of bond that she would have been part of if she had contributed more.

Further evidence of awareness of participating in a community - among the whole cohort - is that the students did not avail themselves of the opportunity to make comments anonymously. Instead, on four of the five occasions in which students neglected to include their names in a comment (and this could easily happen accidentally in our blog platform ${ }^{8}$ ), they were at pains to add a PS-like comment apologising and identifying themselves. And the fifth case was obviously also a slip, which went unnoticed. We saw this as demonstrating confidence in the group's supportive reaction to their comments and concern not to be seen as seeking anonymity.

Other characteristics of students' contributions that we saw as reflecting their sense of participation in a community were: their enjoyment in developing the representation of their own personalities in the blog; their inclusion of self-effacing confessions or joking comments at their own expense; and their preparedness to expose their inexperience or ignorance. These characteristics were present in the 'no effect' group's contributions as well as those of the 'positive effect' group, as the following excerpts from 'no-effect' students illustrate:

- S2: "S9, for those like me who have never tasted a tartufo, can you describe the flavour?" 
- S5: "The other day I was sitting at my desk trying to study without success when I felt a great craving for chocolate. I went to the kitchen, only to discover that we didn't have any chocolate in the house, so I returned to my desk but couldn't manage to study without my chocolate!"

Indeed, one student from the 'no effect' group who demonstrated all these characteristics was S14, who particularly developed his personality through selfmocking observations that he knew would amuse and be well received by the group, such as:

"I have to confess... I never could distinguish a horrendous coffee from an excellent one. I'm sure that, in the eyes of many, I'm a real barbarian." and through his style in addressing the group, as in this example:

"As some people in this class already know, I spent 5 years in the army, and I'd like to apologise to those people because I'm going to relate yet another story about my experience as a soldier."

He also made reflective and appreciative comments on other students' contributions, such as this response to a contribution by a woman with whom he had not been seen to interact much in class:

"Ciao S13, you seem to me to have a very good relationship with your family. In fact, your story has made me feel a bit of nostalgia. In the last nine or ten years I've hardly ever had a meal together with my father or my sister... maybe this Sunday I'll do a roast..."

\section{Discussion}

Our analysis of the questionnaire responses and the blog content suggests that the students not only saw La mensa as a useful tool for practising reading and writing skills, but also experienced it as a community. Through blogging on La mensa, they produced much more written Italian than in our other courses at the same level evidently finding it a valuable opportunity for frequent informal writing - and often engaged in extensive reading. At the same time they clearly felt, and worked to sustain, a strong sense of community. Indeed, the prevalence of a desire to collaborate and to treat each other with respect was remarkable in their online discussion.

We identify three factors that may help explain why La mensa was effective in promoting online participation and connectedness among these students. The first is the blended learning environment of the course "Italy Through Food", which combined the online component of La mensa with face-to-face work in class. The three weekly contact hours undoubtedly played a part in motivating students to pursue discussion online and in fostering class cohesiveness. We do not claim that the blog was solely responsible for creating a sense of community in our students but that it provided novel, additional opportunities for nurturing a feeling of connectedness.

The second factor is the teachers' voice, which we feel may have influenced the students' discursive practices. The importance of attention to establishing and maintaining a constructive social presence in an online environment is highlighted in Rovai's (2007, pp. 82-83) recommendations for online facilitators. In La mensa, whether contributing as facilitators or ordinary participants, the teachers sought to encourage a harmonious tone in the blog discussion, by making encouraging remarks, 
showing respect for ideas and feelings expressed, eschewing an authoritarian stand when presenting their views and abstaining from explicit language correction in the blog comments. ${ }^{9}$ This may help explain why the students tended to maintain a connected voice when interacting, and avoided taking an argumentative stand.

Finally, we think the personal style of communication that La mensa seemed to encourage played a strong community-building role. The students evidently appreciated being able to share their own experiences in relation to the subject matter, and they did this to a much greater extent than we had expected. Indeed, $44 \%$ of contributions to the teacher-initiated threads that we analysed included some recounting of personal stories and perspectives; that is, manifestations of connected voice of type $a$. We see two factors as possibly contributing to this tendency to use the blog for a personal approach to topics and tasks, rather than just to continue academically-oriented discussion outside class. First, the students found writing for the purposes of academic argument, with reference to appropriate sources, more challenging and time-consuming than contributing to discussion by relating personal experiences. Our impression is that they did extend themselves linguistically in the blog, but found it much more efficient to invest their linguistic efforts in personal writing. This is an aspect of their blog use that we will investigate in further research. The second reason comes back to the impact of the teachers' voice on that of the students. From the beginning, the teachers contributed both through entries aimed at stimulating academic discussion and comments that revealed personal experiences, and the students evidently felt that threads were open to both types of content.

Our experience is consistent with that reported in previous studies highlighting the teachers' crucial role in making blogging happen in language courses (Arena, 2008) and in designing an approach to online discussions so as to build a sense of class community (Rovai, 2001). We found our role in La mensa, and especially the striving for a balance between the blog and classroom environments, challenging and professionally enriching. Through the experience we have identified four guidelines for our future integration of blogging into language courses. We do not present these as guidelines for facilitators or moderators in online environments in general, but reflections that may be useful to language teachers who are setting out to create a supportive and effective online learning environment for foreign-language learners, with their specific needs in mind.

First, in the design stage, we consider it essential to integrate the blog component into both the course content and assessment requirements and to explore how best to take advantage of the technical features of blogging in the specific learning context. Practical choices concerning, for example, images and videos, the names of the blog categories, and resources for inclusion in the blog roll, can be very important in helping create a feeling for the students of belonging to a unique group. We deemed it important to incorporate La mensa use into assessment not only for the practical reason of providing a convincing incentive to participate - and the experience of Petersen, Divitini and Chabert $(2008,2009)$ with a non-compulsory blog demonstrates that such incentive may well be necessary - but also on the basis of a general principle of ensuring that the types of assessment in a course reflect its aims and content. 
Second, at the beginning of the course, students need to be provided with clear explanations of not only the blog's technical features but also its function in the specific course and in their own learning. Third, the teachers, as online facilitators, particularly in a blended learning environment, need to think carefully about how to establish a 'connected' blog conversation from the start, and how to contribute in terms of both content and voice throughout the life of the blog, in such a way as to support class community building. This may involve constant reading of students' entries and comments, adding comments to stimulate debate, providing content to better inform students' discussion while leaving it up to them to decide the direction of that discussion, giving specific linguistic help upon request, and identifying general language points that warrant clarification in class. Finally, it is the teachers' responsibility to ensure the blog-classroom connection works both ways, so that class debates are continued online and blog debates resumed in class. In this way, blogging not only extends discussion outside class, but also nourishes and enriches in-class interaction.

\section{Conclusion}

The results of our study suggest that the integration of a class blog into "Italy Through Food" was indeed effective in promoting authentic interaction. The students were able not only to access additional material on course topics outside class, but also to further explore these topics through discussion with their peers. This was beneficial in increasing the students' written production during the semester, stimulating reflection on their personal experiences, and encouraging them to share these with the rest of the group, thus strengthening the sense of community. This positive outcome leads us to set a more ambitious goal for the future: to achieve a mode of using blogs that, while still promoting the sharing of personal experiences, and thereby encouraging collaboration and connectedness, equally favours discussion informed by academic enquiry and critical reading of the posted material. Getting this balance right will be our focus in the next stage.

\section{References}

Arena, C. (2008). Blogging in the language classroom: It doesn't "simply happen". TESL-EJ, 11(44), 1-7.

Campbell, A.P. (2003). Weblogs for use with ESL classes. The Internet TESL Journal, 9(2). Retrieved from http://iteslj.org/Techniques/Campbell-Weblogs.html

Campbell, A.P. (2004). Using LiveJournal for authentic communication in EFL classes. The Internet TESL Journal, 10(9).Retrieved from http://iteslj.org/Techniques/Campbell-LiveJournal/

Castro, J. (2007). El uso de blogs en la clase de español. Una herramienta de apoyo al aprendizaje autónomo [Using blogs in the Spanish classroom. A supporting tool for independent learning]. Biblioteca Virtual, 7. Retrieved from http://www.educacion.es/redele/Biblioteca2007/JavierCastro.shtml

Dörnyei, Z. (1997). Psychological processes in cooperative language learning: Group dynamics and motivation. The Modern Language Journal, 81(4), 482-493.

Dörnyei, Z. (2001). New themes and approaches in second language motivation research. Annual Review of Applied Linguistics, 21, 43-59. 
Dörnyei, Z. (2007). Creating a motivating classroom environment. In J. Cummins, \& C. Davison (Eds.), International handbook of English language teaching Vol. 2 (pp. 719-731). New York: Springer.

Dörnyei, Z., \& Murphey, T. (2003). Group dynamics in the language classroom. Cambridge: Cambridge University Press.

Ducate, L., \& Lomicka, L. (2005). Exploring the blogosphere: Use of web logs in the foreign language classroom. Foreign Language Annals, 38(3), 410-422.

Ducate, L., \& Lomicka, L. (2008). Adventures in the blogosphere: from blog readers to blog writers. Computer Assisted Language Learning, 21(1), 9-28.

Egbert, J. (2006). The end of CALL and how to achieve it. Teaching English with Technology: A Journal for Teachers of English, 6(2).

Godwin-Jones, R. (2003). Emerging technologies. Blogs and wikis: Environments for on-line collaboration. Language, Learning and Technology, 7(2), 12-16.

Godwin-Jones, R. (2006). Tag clouds in the blogosphere: Electronic literacy and social networking. Language Learning \& Technology, 10(2), 8-15.

Lee, J.S. (2006). Exploring the relationship between electronic literacy and heritage language maintenance. Language Learning \& Technology, 10(2), 93-113.

Miceli, T., \& Visocnik Murray, S. (2005). Strategy training: Developing learning awareness in a beginning FL classroom. In B.Bartlett, F. Bryer, \& D. Roebuck (Eds), Stimulating the "action" as participants in participatory research (pp. 1525). Brisbane, Australia: School of Cognition, Language and Special Education, Griffith University.

Murray, L., \& Hourigan, T. (2008). Blogs for specific purposes: Expressivist or sociocognitivist approach? ReCALL, 20(1), 82-97.

Petersen, S.A., Divitini, M., \& Chabert, G. (2008). Identity, sense of community and connectedness in a community of mobile language learners. ReCALL, 20(3), 361379.

Petersen, S.A., Divitini, M., \& Chabert, G. (2009). Sense of community among mobile language learners, can blogs support this?. International Journal of Web Based Communities, 5(3), 428-445.

Pinkman, K. (2005).Using blogs in the foreign language classroom: Encouraging learner independence. The JALT CALL Journal, 1(1), 12-24.

Richardson, W. (2006). Blogs, Wikis, Podcasts, and Other Powerful Web Tools for Classrooms. Thousand Oaks, California: Corwin Press.

Roed, J. (2003) Language learner behaviour in a virtual environment. Computer Assisted Language Learning, 16(2-3), 155-172.

Rovai, A. (2001). Building classroom community at a distance: A case study. Educational Technology, Research and Development, 49(4), 33-48.

Rovai, A.P. (2002). Development of an instrument to measure classroom community. Internet and Higher Education, 5(3), 97-211.

Rovai, A. (2007). Facilitating online discussions effectively. Internet and Higher Education, 10, 77-88.

Stanley, G. (2005, March 06). Blogging for ELT. Teaching English. Retrieved from http://www.teachingenglish.org.uk/think/articles/blogging-elt

Stevens, V. (2004). Tools for building online communities. Essential Teacher, Spring, 32-35.

Tan, Y. H., Ow, J. E. G. \& Ho, J. M. P. Y. (2005). Weblogs in education. IT Literature Review. Retrieved from http://www.edublog.net/files/papers/weblogs\%20in\%20education.pdf 
Van Lier, L. (1996). Interaction in the Language Curriculum: Awareness, Autonomy and Authenticity. London: Longman.

Ward, J.M. (2004). Blog Assisted Language Learning (BALL): Push button publishing for the pupils. TEFL Web Journal, 3(1).

\footnotetext{
${ }^{1}$ In the 2001 study Rovai used the SCCI or Sense of Classroom Community Index (Rovai \& Lucking 2000 cited in Rovai, 2001, p.34), a forerunner of his Classroom Community Scale referred to above.

${ }^{2}$ In this section, the pronouns 'we', 'us' and 'our' refer to the two authors who created the course and the blog: Miceli and Visocnik Murray.

${ }^{3}$ At the time of creating La mensa, no wiki with a comment facility and the equivalent of a blog roll was available in our institutional environment as an alternative to the blog.

${ }^{4}$ We are grateful to Ben Jenkins for his invaluable technical support in the use of the blog feature of Lotus Notes.

${ }^{5}$ In interpreting the students' contributions we took into account the use of punctuation and emoticons as well as words. That is, a contribution could be included in one of the above categories if its use of exclamation marks, italics, capitals or emoticons appeared to indicate that a particular slant was to be put on the words in line with that category.

${ }^{6}$ The translations of students' blog contributions used in this paper are by the authors and are as faithful to the original as possible.

${ }^{7}$ The Mann-Whitney U test serves to assess whether two samples can be considered as drawn from the same population or not.

${ }^{8}$ When a comment was added, the system did not automatically insert the writer's name; nor did it remind the writer to do so. Furthermore, once a comment was added it could not be modified, so the writer had to deliberately make a second comment to add a name, or indeed to change anything.

${ }^{9}$ To address any recurring language issues in the students' comments we used implicit forms of feedback (such as recasts) in the online conversation, so as not to interrupt its flow, and then sought to address the issues explicitly in class.
} 